\title{
Intoxication of a dog with alkaloids of the fire salamander
}

\author{
VLADIMIRA ERJAVEC, BARBARA LUKANC, JURIJ ŽEL
}

University of Ljubljana, Veterinary Faculty, Small Animal Clinic, C. v Mestni log 47, SI-1000 Ljubljana, Slovenia

\section{Erjavec V., Lukanc B., Žel J. \\ Intoxication of a dog with alkaloids of the fire salamander}

Summary

The fire salamander (Salamandra salamandra) belongs to amphibians and is widespread in natural habitats over Europe. Its distinctive black-yellow skin produces toxic alkaloids in the dorsal and parotoid skin glands. These alkaloids can cause clinical signs of intoxication and may lead to death of an animal after mucosal contact or ingestion of the fire salamander. Although there are many anecdotal reports on dog intoxication with the salamander, there are no published data available for that kind of intoxication. We assume that this is due to the fact that most dogs die after intoxication with toxic alkaloids of the fire salamander. This paper describes the clinical case of a dog which survived the intoxication after the contact with a fire salamander. Publication of this case report has a certain value to those people who deal with dogs because contacts of dogs with salamanders are not rare, but so far there is no publication in the literature on survival of a dog after biting a fire salamander.

Keywords: Salamandra salamandra, toxicity, neurotoxic samandarin and samandaron, dog

The fire salamander (Fig. 1), a member of the Salamandridae family, is distributed through large parts of Western, Central, and Southern Europe, including the main three Mediterranean peninsulas: the Iberian, Apennine, and Balkan (9). It is found in woodland habitats covering most of Slovenia, especially near ponds or streams. It spends much time beneath rocks or logs, or hiding in crevices to stay protected and moist $(3,10)$.

The bright yellow-black skin and its toxic alkaloids, produced in the parotoid and dorsal skin glands (2), are the defense mechanism of the fire salamander against predators. The most important alkaloids produced are

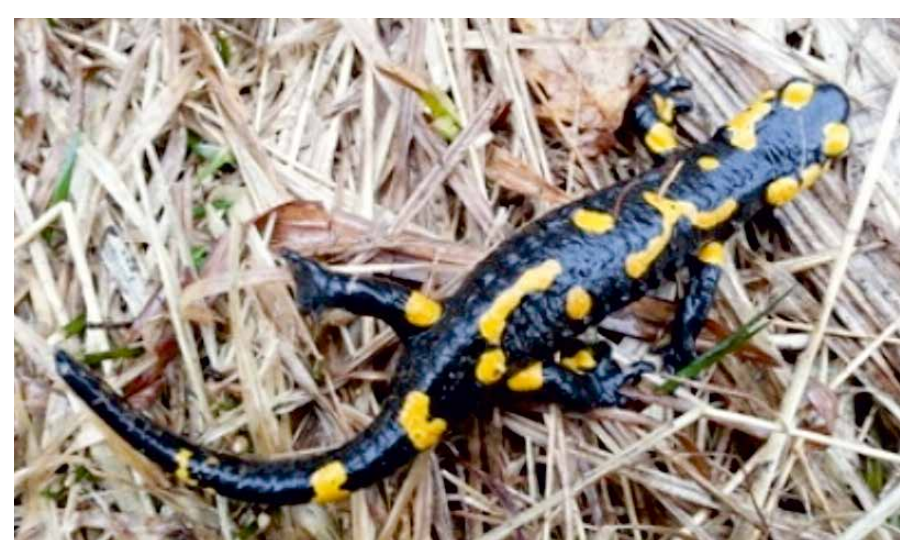

Fig. 1. Fire salamander (Salamandra salamandra) neurotoxic samandarin and samandaron. They play a protective antimicrobial and antifungal role on the skin of the fire salamander (8) and may reach quantities up to $20 \mathrm{mg}$ in the dorsal and parotoid glands (2). The quantity and the ratio of the alkaloids found in the fire salamander vary between individuals of the same species as well as between other species of the same family (11).

The fire salamander can also spray its toxic alkaloids from the 1.5 to $1.8 \mathrm{~mm}$ large middorsal row of skin glands in the direction of a predator in defense situations without application of external pressure $(1,3)$. When doing this, the salamander takes a threatening posture, extends its legs, thereby elevating and tilting its body toward a predator which helps to spray the secretions towards it in up to $200 \mathrm{~cm}$ distance. When multiple glands are sprayed, they are often from widely different parts of the dorsal gland rows, suggesting complex control over the spraying process. The fire salamander does not spray from parotoid glands and lateral warts because these glands are not surrounded by skeletal muscles (1).

\section{Case description}

A 12-year-old mix breed female dog weighing $6 \mathrm{~kg}$ was presented to our clinic. According to the owner, the dog had bitten a fire salamander about 15 minutes prior to presen- 
tation. The owner immediately flushed the mouth of a dog with water to remove the toxic alkaloids. Within a few minutes the dog became dyspnoeic and convulsions appeared.

At the time of presentation the dog had muscle tremors and seizures with apneustic agonal breathing and hypersalivation. The dog was in lateral recumbency and only poorly responding to tactile stimuli, hyperthermic with rectal temperature of $40.7^{\circ} \mathrm{C}$, with pulse of $100 / \mathrm{min}$ and had cyanotic mucous membranes. The clinical condition of the dog deteriorated progressively in the following few minutes in spite of immediately initiated treatment. The dog stopped breathing; therefore, it was immediately intubated and ventilated with $100 \%$ oxygen. At the same time the mouth was additionally flushed with water. Ten minutes later the dog began with spontaneous shallow and accelerated breathing. After extubation, oxygenation via an oxygen mask was continued for one hour. Simultaneously, fluid therapy with lactated Ringer's solution (Hartmannova raztopina Braun, B Braun, Melsungen, Germany) at a rate of $5 \mathrm{ml} / \mathrm{kg} / \mathrm{h}$ was initiated and cooling the dog with cold packs and wet towels was induced. Ten minutes after extubation mucous membranes became brick-red with shortened capillary refill time. Muscle tremors and epileptiform seizures with opistotonus became more pronounced with a duration of up to one minute. Seizures were controlled with $0.16 \mathrm{mg} /$ $\mathrm{kg}$ midazolam intravenously (Midazolam Torrex $1 \mathrm{mg} / \mathrm{ml}$, Chiesi Pharmaceuticals GmbH, Vienna, Austria). Urinary catheter was administered and urine production monitored regularly. First hour urine production was $1.5 \mathrm{ml} / \mathrm{kg}$ and increased to $2 \mathrm{ml} / \mathrm{kg} / \mathrm{h}$ in the next four hours. The dog vomited once after the initiation of the therapy.

After one hour of therapy rectal temperature dropped to $38.5^{\circ} \mathrm{C}$, the $\operatorname{dog}$ was responsive and started to lift its head but was still unable to stand on its own. Half hour later the dog was standing but was still ataxic, with slight tremors and hypersalivation. The dog received ranitidine $2 \mathrm{mg} / \mathrm{kg}$ (Ranital 25 mg/ml, Lek, Ljubljana) intravenously. Four hours after initial treatment, the rectal temperature dropped to $37.8^{\circ} \mathrm{C}$ and all clinical signs resolved. The follow up of the dog revealed no relapses of clinical signs related to alkaloid intoxication.

\section{Discussion}

Poisoning with alkaloids of fire salamander in humans is very rare and without fatality so far. Poisoning in animals may occur occasionally, and an occasional case is reported when a hunting dog plays with a salamander, gets sick and finally dies. Cats on the other hand, avoid touching salamanders and stay away, possibly due to a special smell (6).

Because of the rapid and high mortality of dogs in contact with salamanders many affected dogs are not presented to the veterinarian on time or they die soon after arrival to the clinic. We assume that for this reason the literature on the matter is so scarce. While investigating literature we came to anecdotal reports from the web community on salamander intoxication in dogs which did not survive. We assume that in our case the immediate and rational reaction of the owner who rinsed the mouth of a dog with drinking water from a bottle was crucial for the survival of the dog during immediate transportation to the clinic. Despite this the condition of the dog deteriorated so seriously that it was presented with agonal breathing, hyperthermic, cyanotic and in convulsions. Therefore, immediately after the arrival to the clinic intense therapy was started.

Little is known about the mechanisms of toxicity of the fire salamander's toxic alkaloids. They are strong poisons acting on the central nervous system of vertebrates (7), particularly the spinal cord (11), causing clonic convulsions and paralysis, hyperventilation and arrhythmias. Irritation of the mucous membranes is a common part of clinical presentation $(5,7)$. Treatment of the intoxication is symptomatic. Mucous membranes contaminated with toxic alkaloids have to be rinsed with copious amounts of water as soon as possible to prevent further absorption. Alkaloids may lead to asphyxia due to respiratory paralysis, which primarily results in death (7), which nearly happened in the presented dog. After breathing the dog manually and additionally rinsing the dog's mouth it started to spontaneously breathe shallow and accelerated.

Convulsions can be controlled with benzodiazepines or barbiturates. In our case we used midazolam and the convulsions resolved. Eventual bradyarrhythmias can be treated with atropine. Tachyarrhythmias, on the other hand, are treated with propranolol or esmolol. Because the heart rate was regular at all times, and between 98 and 101 per minute, antiarrhythmic drugs and atropine were not used. Fluid therapy is essential for cardiovascular support so we used lactated Ringer's solution.

Prognosis depends on the severity of the clinical presentation. If only mild clinical signs are present, the prognosis is good but it worsens with the severity of the clinical signs. If the salamander was ingested and the only clinical presentation is hypersalivation, emesis can be induced. In case of other clinical signs endoscopic or surgical removal may be considered after initial stabilization of the animal. Alternatively, charcoal or laxatives can be administered (4).

Without prompt first aid, when ingested or with mucosal contact of a dog the toxic alkaloids of the fire salamander can cause pronounced clinical manifestation and instant death. Therefore, it is essential to educate owners about the first aid they can provide to a dog after contact with the fire salamander. Our case indicates that the dog can survive contact with a fire salamander but only if the therapy is aggressive, symptomatic and starts as soon after the contact as possible.

\section{References}

1. Brodie E. D., Smatresk N. J.: The antipredator arsenal of fire salamanders: spraying of secretions from highly pressurized dorsal skin glands. Herpetologica 1990, 46, 1-7.

2. Daly J. W., Garraffo H. M., Spande T. F., Pelletier S. W.: Alkaloids: Chemical and Biological Perspectives. Elsevier Science, Oxford 1999, p. 3-5.

3. Griffiths R. A. (Ed.): Newts and Salamanders of Europe. Poyser; Academic Press, London 1996, p. 188. 
4. Gwaltney-Brant S. M., Dunayer E. M., Youssef H. Y.: Terrestrial zootoxins, Gupta R. C. (ed.), Veterinary Toxicology Basic and Clinical Principles. Elsevier, New York 2007, p. 785-810.

5. Habermehl G.: Amphibia, [in:] Habermehl G. (ed.): Venomous Animals and their Toxins. Heidelberg, Springer, Berlin 1981, p. 112-129.

6. Habermehl G.: Antimicrobial activity of amphibian venoms, [in:] Atta-ur-Rahman (ed.): Studies in Natural Products Chemistry. Vol. 15, Part C, 1995, p. 327-339.

7. Habermehl G.: Venoms of amphibia, [in:] Florkin M., Scheer B. T. (eds.) Chemical Zoology 9. 1 ed., Academic Press, New York 1974, p. 161-183.

8. Habermehl G., Hammann P. E., Krebs H. C., Ternes W.: Biogene Amine und Alkaloide, [in:] Habermehl G., Hammann P. E., Krebs H. C., Ternes W. (eds.): Naturstoffchemie eine EinffEinf. n: Springer Verlag, Berlin 2008, p. 143-249.

9. Jablonski D., Balej P., Juna F., Homolka M.: Low altitudinal distribution of Salamandra salamandra from the Balkan Peninsula. Herpetology Notes 2013, 6, 563-566.

10. Lešnik A., Poboljšaj K.: Prispevek k poznavanju favne dvoživk (Amphibia) severovzhodne Slovenije. Natura Slovenije 1999, 1, 71-82.

11. Mebs D., Pogoda W.: Variability of alkaloids in the skin secretion of the European fire salamander. Toxicon 2005, 45, 603-606.

Corresponding author: Assist. Prof. Vladimira Erjavec DVM, MSc, PhD Small Animal Clinic, Veterinary Faculty, University of Ljubljana, C. v Mestn $\log$ 47, SI-1000 Ljubljana, Slovenia; e-mail: vladimira.erjavec@vf.uni-lj.si 